\title{
A Regionalização da Inovação Agroecológica Social: discussões acerca da coletivização do conhecimento agroecológico num recorte regional
}

\author{
The Regionalization Social Agroecological Innovation: \\ discussions about the collectivization of agroecological \\ knowledge in a regional perspective
}

\section{La regionalización de la innovación agroecológica social: las discusiones sobre la colectivización del conocimiento agroecológico en un recorte regional}

\author{
Luciano Ricardio de Santana Souza \\ gladiuslucius@gmail.com \\ Universidade Federal de Sergipe
}

\begin{abstract}
Resumo: A forma de produção do conhecimento inovador social abrangeu, na última década, não apenas as áreas urbanas, mas também o espaço rural, de onde se observa os impactos da junção entre o saber produtivo ancestral e as bases de decodificação coletivo-científica das técnicas de produção ecológica. De igual modo, a agroecologia emerge como prática de concretização da junção entre o agrícola tradicional e o conhecimento científico, tendo nas inovações sociais agrícolas o seu ícone de continuidade. Desta forma, a inovação social agroecológica encontra na trama das redes produtivas regionais os elementos ideais de sua propagação.
\end{abstract}

Palavras-chave: Regionalização. Inovação. Agroecologia social.

Abstract: The production form of social innovative knowledge included, in the last decade, not just the urban areas, but reappeared in the country areas, where we can observe the impacts of the junction between the ancestral productive knowledge and the scientific-collective techniques decoding bases of the ecological production. Similarly, the agroecology emerged as a practical realization of the junction between the traditional agricultural and scientific knowledge, having in the social agricultural innovation its icon of continuity. Thus, the social agroecological innovation finds in the regional productive networks its ideal elements of its spread.

Keywords: Regionalization. Innovation. Social agroecology.

Resumen: La forma de producción del conocimiento innovador social abarcó, en la última década, no solo las áreas urbanas, pero resurge en el espacio rural donde se observa los impactos de la unión entre el saber productivo ancestral y las bases de la descodificación colectiva científica de las técnicas de producción ecológica. Del mismo modo la agroecología emerge como práctica de concretización de la unión entre el conocimiento tradicional agrícola y el conocimiento científico, teniendo en las 
innovaciones sociales su ícono de continuidad. Por lo tanto, la innovación agroecológica encuentra en la trama de las redes regionales productivas, los elementos ideales para su propagación.

Palabras claves: Regionalización. Innovación. Agroecologia social.

\section{INTRODUÇÃO}

A busca por melhoria nos processos de produção agrícola, por parte das famílias agricultoras, permitiu o surgimento de novas técnicas de cultivo e de trato da terra, caracterizando uma maior diversificação de ocupações e geração de alternativas de renda para os produtores rurais.

A expressão da engenhosa capacidade de atualizar estratégias para permanecer na atividade agrícola frente a contextos desfavoráveis possibilitou a transmissão de conhecimento por intermédio da valorização dos saberes ancestrais. Em vez de trilhar caminhos que os subordinam progressivamente a uma lógica mercantil estranha aos seus modos de vida e incompatível com os meios de produção, buscam a construção de crescentes níveis de autonomia por meio da combinação de atividades agrícolas, do conhecimento científico e da sabedoria produtiva popular. Ao mesmo tempo em que permitem reforçar a sua identidade de agricultor, os produtores rurais conseguem manter a sua sobrevivência e reprodução social.

A noção de que o progresso social e econômico no campo parte de novas inserções tecnológicas sociais, constituindo uma ruralidade de múltiplas facetas, resgata e reafirma a importância do conjunto de criações coletivas dos produtores rurais. Essas criações coletivas dos produtores rurais concebem a difusão técnico-produtiva social e solidária por intermédio da regionalização da inovação social agrícola. Essa discussão, no artigo em foco, pretende contribuir teoricamente para o entendimento acerca da coletivização do conhecimento e da inovação agroecológica num recorte regional.

\section{AS FORMAS DE PRODUÇÃO NA TRANSIÇÃO AGROECOLÓGICA}

As estratégias agroecológicas têm que apontar deliberadamente para os agricultores pobres, não somente para aumentar a produção e conservar os recursos naturais, mas também para gerar emprego, promover a formação da renda e oferecer oportunidades de acesso aos mercados locais.

Qualquer tentativa séria para desenvolver tecnologias agrícolas sociais sustentáveis a partir das experiências e saberes dos próprios agricultores e da sua inserção à transição agroecológica deve associar-se à formação e ao planejamento das técnicas de produção convencional ou ancestral. Assim, a preocupação em conceber os elementos 
socioprodutivos ${ }^{1}$ mais condizentes com as potencialidades locais promove uma forma autônoma de atividade agrícola bem distinta da agricultura absorvida pelo agronegócio. Daí, não há espaço para a monocultura comercial, mas apenas para as formas produtivas agrícolas e pecuárias mais integradas com a natureza e com as necessidades e particularidades culturais das comunidades camponesas.

Para Petersen et al. (2009, p.117), a disjunção entre produção e as especificidades ambientais e socioculturais, que compõem os territórios rurais, deu-se à medida que, na modernidade, os mercados assumiram papel preponderante como componente de regulação da sociedade. A modernização da agricultura retirou do agricultor o controle do conhecimento associado ao seu próprio trabalho, criando um mecanismo que, ao mesmo tempo, expropria o saber-fazer das comunidades rurais e transfere esse poder para as corporações do agronegócio transnacional. Dessa forma, a dependência tecnológica converteu-se em invasão cultural, imobilizando as capacidades autônomas de inovação local e promovendo a desconexão da agricultura em relação aos ecossistemas, às comunidades e ao consumo de alimentos (PETERSEN et al., 2009, p. 123).

O saber das comunidades agrícolas tradicionais foi, por muito tempo, subestimado pelos cientistas, que negligenciavam outras formas ou sistemas de conhecimento não estritamente científicos ou confinados à academia. A valorização do saber tradicional, por parte dos etnobiólogos e etnoecólogos, tem produzido alternativas tecnológicas sociais e ambientais no campo, seguindo os paradigmas correntes de autonomia camponesa, com efeitos benéficos para o conhecimento científico-acadêmico e coletivo (PERTERSEN, 2007, p.15).

Segundo Marques (2009, p. 58), o processo de inovação e disseminação tecnológica agrícola social, por intermédio de metodologias de produtor a produtor, que estão baseadas no compartilhamento das experiências, no fortalecimento das capacidades da investigação local e na resolução dos problemas, garante a prevalência do processo agroecológico, proporcionando o melhoramento do nível cultural ecológico dos agricultores no decorrer de suas explorações agrícolas e de manejo dos recursos naturais. Tais práticas ocorrem centradas nas bases de potencialização, de constante inovação rural coletiva e inclusiva e de dinamização das alternativas de autofinanciamento das comunidades rurais.

De acordo com Petersen et al. (2009, p.145), a agroecologia possui uma dimensão integradora, pois pode potencializar-se pela junção entre as práticas agrícolas e não-agrícolas como a agroindústria e o turismo rural, nos quais as variáveis sociais ocuparão um papel relevante a partir da dimensão técnica, em nível de análise da superação das formas de dependência (tecnológicas, produtivas e financeiras). Assim sendo, a agroecologia não apenas insere um novo padrão produtivo agrícola, mas interliga-se a outras

1 Os elementos socioprodutivos prendem-se ao aspecto das formas produtivas distanciadas da captação capitalista do excedente gerado. O que resulta como excedente e os meios de produção devem pertencer aos atores envolvidos no processo (agricultores e operários). É a lógica fundamental da Economia Solidária (Nota do Autor). 


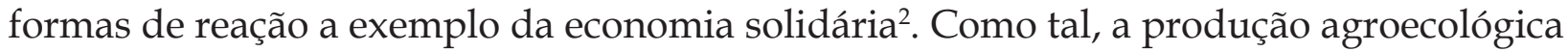
social "tem outros níveis de análise" (para além do nível técnico ou concentracionista), "que consideram a prática agrícola ecológica como central a matriz sociocultural, predispondo uma práxis intelectual e política à sua identidade local e à sua rede de relações sociais, econômicas e produtivas" (PLOEG, 2009, p. 24).

Em síntese, os processos agro-produtivos ${ }^{3}$ de transição da agricultura química para a agricultura ecológica camponesa devem desenvolver-se nos contextos sócio-culturais das unidades familiares, supondo propostas coletivas e auto-gestoras de transformação da estrutura rural (PLOEG, 2009, p. 25).

O contexto teórico estabelecido pelo conceito de agroecologia, aqui utilizado, permite caracterizá-lo como prática produtiva onde as "comunidades de agricultores tradicionais" constituem um grupo que desenvolve uma forma de cultivo social, pelo qual se convertem, até hoje, as atividades produtivas em formas de convivência sociedade-natureza. Estas formas de cultivo social têm sido denominadas "sociedades de base produtiva natural ou sociedades orgânicas", as quais motivam uma nova proposta econômica (PLOEG, 2009, p.58). As economias de base orgânica somente poderiam funcionar com um tipo de produtor rural que possuísse as determinadas características: economia de base familiar e mobilização de todo o pessoal disponível para o trabalho agrícola (os mutirões).

A existência de relações de apoio mútuo, mediado por relações de parentesco ou por amizade com os vizinhos, em um contexto cultural em que prevalece a ética social ou coletiva, insere táticas novas de usos múltiplos do território rural (VANDERLEY, 2009, p.89). Assim, a forma de resistência e solidariedade social emerge como uma estratégia de diversificação de ações diante de riscos climáticos ${ }^{4}$, econômicos, mercadológicos e produtivos.

Para Marques (2009, p. 60), a economia sócio-orgânica e solidária, que surge com o fortalecimento das ações de convivência agricultura-natureza nas comunidades rurais tradicionais, é, em termos agroecológicos, uma forma de relacionamento que considera o processo de co-evolução como o produto de promoção de formas técnicas sociais baseadas na renovação contínua dos elementos naturais do solo e da vegetação do entorno e na redistribuição dos seus resultados (os rendimentos).

Na opinião de Petersen (2007, p. 45), a prática agroecológica é uma consequência de uma opção teórica por uma abordagem sistêmica e holística de produção agrícola e manejo ecológico, que carrega consigo os pressupostos naturalistas, a partir dos quais a sociedade pode ser estudada pelos mesmos métodos, démarches e processos empregados nas ciências da natureza. Diante de tal perspectiva, concebe-se um caminho distinto, tratando a agroecologia como uma prática político-social mobilizada como instrumento

2 Economia Solidária compreende alternativas de geração de renda baseadas na autogestão social do processo produtivo (Nota do Autor).

3 Os processos agroprodutivos são relações baseadas no uso do solo e nas práticas de cultivo agrícola (Nota do Autor).

4 A exemplo das formas camponesas de convivência com os desníveis climáticos, pode-se observar o contexto de surgimento da Articulação com o Semi-Árido Brasileiro (ASA) que redefiniu novas estratégias de convivência dos sertanejos nordestinos e mineiros com as secas severas, retirando do entorno novos significados e identidades (Nota do Autor). 
de resistência no conflituoso universo das relações que os produtores rurais estabelecem quando há a busca por estratégias contra o capital comercial e industrial. Neste sentido, a forma de reação dos camponeses ao capitalismo será tomada como referência fundamental para o entendimento das práticas agroecológicas enquanto ações que buscam uma autonomia amparada em um mecanismo de resistência política. Dele surge o uso da agroecologia como forma produtiva vinculada às estratégias e vivências sociais, produtivas e econômicas do agricultor, percebem-se as formas discordantes de construção dos territórios rurais: uma sobre a lógica socioambiental e outra oriunda da agricultura de precisão (PETERSEN, 2007, p. 45).

Então, a sociologia agroecológica, no tocante à concepção de Ploeg (2006, p. 59), deve servir para identificar o produtor agroecológico na história por sua forma de trabalhar o território rural e desenvolver o conhecimento que sustenta cada forma específica de trabalho e de manejo dos recursos naturais. Dessa forma, o produtor rural pode ser considerado, numa perspectiva agroecológica, como "uma categoria histórica" que sabe manter "as bases de reprodução biótica dos recursos naturais". Nessa perspectiva, é possível tratar de "reconstrução" ou grau de "reinvenção" social do Espaço Rural em termos supremacia, solidariedade e autonomia dos grupos de produtores agrícolas sob a predominância da transição, cultura e criatividade agroecológica.

\section{A CULTURA E A CRIATIVIDADE NO DESENVOLVIMENTO DA AGROEOCOLOGIA SOCIAL}

A cultura converte-se em formas, conteúdos, símbolos, crenças e identidades. Em resumo, transforma-se em valores, sobre os quais as pessoas produzem ou idealizam os lugares. A capacidade criadora da cultura potencializa os arranjos produtivos locais quando converte os valores sociais em valores produtivos.

Segundo Amaral Filho (2009, p.1), a economia da cultura apresenta-se como produção social, atribuindo conteúdo aos lugares e dependendo das dotações humanas e materiais, que são oriundas da cultura e potencializam as capacidades criativas endógenas dos atores locais. Estes concluem a sua atividade criativa com a articulação, organização e manifestação dos saberes locais. Amaral Filho (2009, p.1) discute que a criatividade pode "estar em todos os indivíduos, em todo lugar, pois não obedece a nenhuma determinação física ou natural para emergir, e se apresenta como potencializador da capacidade dos atores produtivos". Tudo o que surge dos processos criativos sociais é disposto gratuitamente como inovação coletiva, colocando em ênfase todas as perícias e todas as ações produtivas, originando novas adaptações e objetos oriundos da habilidade dos indivíduos e suas formas de idealização do seu entorno.

Sobre as orientações de Scott (2010, p. 119), percebe-se que a criatividade ressurge como formas distintas de aprendizagem com base no elo entre a criação e a inovação. Assim, a aprendizagem fornece informações importantes para a atividade criativa, promovendo a produção de novas ideias e novas percepções que podem ser destinadas a 
diferentes finalidades. O elo entre a criação e a inovação possibilita que novos objetos sejam gerados e diagramados seguindo uma gama de necessidades específicas. A relação entre a agroecologia social e a criatividade resulta na forma de propagação regional da inovação na produção agrícola, atribuindo ênfase no saber das comunidades rurais e as suas estratégias de sobrevivência, mesmo em ambientes e contextos desfavoráveis. Este fato interliga a agricultura às atitudes autônomas de difusão do conhecimento ativando as próprias regiões agrícolas segundo um novo aparato criativo e ancestral das formas de produção agrícola dos pequenos agricultores (FREIRE et al., 2006, p. 10-11).

\section{DIMENSÕES REGIONAIS DA INOVAÇÃO SOCIAL AGROECOLÓGICA}

A dimensão de alcance de novos objetos e ações nas regiões agrícolas prende-se aos princípios de localização e extensão (GOMES, 2010, p.53). No âmbito da localização, observa-se onde ocorrem as formas produtivas agrícolas socialmente viáveis, incorrendo para a difusão das formas inovadoras sociais de cultivo. Quanto à extensão, observa-se a abrangência da difusão do conhecimento social agrícola num recorte regional. Tal fato abre campo para a análise da regionalização da inovação agroecológica sobre diferentes aspectos.

Weid (2009, p.59a) propõe a análise sobre um novo "lugar" para a agricultura no tocante à superação dos fatores de insustentabilidade que caracterizam o sistema agrícola comercial baseado nos princípios da Revolução Verde. Os novos estilos de produção agrícola deverão ser econômicos nos recursos naturais e nos usos de insumos técnicos. Para Weid (2009, p.59), as inovações de base agroecológica demonstram sua adequação para as dimensões e formas de gestão do trabalho da agricultura familiar.

Segundo Almeida (2009, p. 75), a centralidade das experiências de inovação local, no fomento da agroecologia familiar, tem primado por situar as descobertas técnicas sociais ${ }^{5}$ como ponto de partida e de chegada para a interação entre as práticas sociais de transformação do meio, a produção compartilhada de conhecimentos e os processos político-organizativos dos quais provém uma gama de criatividades produtivas dos agricultores agroeocológicos. Assim o enfoque inovador da agroecologia concebe a difusão num recorte regional das experiências concretas, refundamentando estratégias de produção e compartilhamento de conhecimento altamente ajustado aos respectivos contextos e reproduzindo métodos de comercialização e a discussão de resultados, que fortalecem a capacidade de dinamismo das organizações e redes locais de arranjos produtivos agrícolas sustentáveis.

Como ciência da agricultura sustentável, a Agroecologia ${ }^{6}$ se expressa regionalmente como uma ciência dos lugares (CAPORAL et al., 2006, p.3). Seu conceito geral só

5 Faz-se menção especial às Tecnologias Sociais (Nota do Autor).

6 "Ademais, como ciência integradora a Agroecologia reconhece e se nutre dos saberes, conhecimentos e experiências dos(as) agricultores(as), dos povos indígenas, dos povos da floresta, dos pescadores(as), das comunidades quilombolas, bem como dos demais atores sociais envolvidos em processos de desenvolvimento rural, incorporando o potencial endógeno, isto é, presente no 'local'" (CAPORAL et al., 2006, p.02) 
ganha, assim, plena significação na difusão regional quando é objetivada em condições específicas, aprimorando-se e se reconstruindo permanentemente no confronto com a própria realidade. Ao se objetivarem as condições biofísicas e socioculturais peculiares em que se desenvolvem as experiências inovadoras, o conceito de Agroecologia se torna concreto e adaptado à situação criativa dos produtores rurais em diferentes contextos espaciais (CAPORAL et al., 2006, p. 6).

\section{A FORMAÇÃO DA CULTURA INOVADORA DOS PRODUTORES AGROECOLÓGICOS E SUA DIFUSÃO NUMA ESCALA REGIONAL}

No processo atual de difusão do sistema produtivo agroecológico social, a ambiência regional das experiências produtivas de agricultores familiares compreende o espaço rural como um lugar de uma sociabilidade mais complexa que aciona novas redes sociais. Essas novas redes envolvem a reconversão produtiva (diversificação da produção), a reconversão tecnológica (tecnologias alternativas de cunho agroecológico e natural) e a democratização da organização produtiva e agrária (reforma agrária e fortalecimento da agricultura familiar).

Os processos de revalorização do mundo rural consolidam atividades rurais e técnico-científicas, reduzindo o êxodo e o desemprego nas áreas rurais e implantando ações locais baseadas na consolidação do planejamento e da gestão social dos arranjos produtivos locais ligados à agroecologia social. De acordo com Moreira (2007, p. 90), a compreensão dos aspectos culturais inovadores nas áreas rurais conduz a hegemonia das forças sociais e do interesse de projeção dos lugares por intermédio da emergência ou da formação de uma cultura inovadora por parte dos produtores agroecológicos.

A influência dos valores associados às iniciativas tecnológicas sociais promoveu a difusão espacial das novas técnicas de produção sustentável pela transmissão do saber, criando-se programas e relações inovadoras verticalizadas por meio da interação das famílias agricultoras. Além de apresentar suas inovações, esses instrumentos dão visibilidade às histórias de vida das famílias agricultoras ou à trajetória de um determinado grupo de produtores, sinalizando seus problemas e dificuldades práticas. As soluções encontradas e, sobretudo, os caminhos percorridos para o desenvolvimento da inovação focalizada regionalmente são concebidos com base em instrumentos coletivos (gestão e planejamento agrícola participativo), que procuram evidenciar as capacidades criativas dos indivíduos ou de grupos de pequenos produtores locais no enfrentamento dos obstáculos do cotidiano (FREIRE et al., 2006, p. 12).

Para que os agricultores e as agricultoras experimentadores se apropriem efetivamente do material produzido, é necessário que a concepção inovadora final seja fiel às suas ideias, falas e pensamentos e que sua cultura e valores sejam respeitados. Quando a produção agrícola retorna aos agricultores e às agricultoras, para que possam conhecer e ajustar o conteúdo produtivo, os procedimentos são sistematizados pela experiência, pois serão os próprios 
conhecimentos adquiridos de geração a geração que farão a distribuição dos saberes numa dinâmica produtiva e inovadora regional (HERNÁNDEZ; HERNÁNDEZ, 2010, p.36).

Em destaque, as trajetórias das pessoas e/ou grupos em seus processos de inovação agroecológica são aspectos centrais das narrativas apresentadas. Em muitas situações, as inovações apresentam alta aplicabilidade em contextos distintos dos quais foram desenvolvidas.

No entanto, ao explicar os princípios e fundamentos associados à inovação agroecológica, estimula-se que outros grupos ou indivíduos situados em outras localidades se ajustem às suas realidades específicas ao conduzirem suas próprias experimentações. Ao apresentar a inovação agroecológica sistematizada no contexto no qual ela foi desenvolvida e experimentada, o material técnico social agrícola realça o potencial criativo e as formas de experimentação e organização adotadas por famílias agricultoras tradicionais. Esse realce exerce um papel importante ao elevar a autoestima dos inovadores sociais e ao motivar outras pessoas e grupos a também ingressarem nas redes regionais de inovação local agroecológica (SOUZA, 2010, p. 20-25).

Enriquez (1997, p. 33) apresenta a existência de duas teorias principais que fazem referência às inovações em relação às organizações: uma que indica que as inovações emanam das grandes organizações, centrais, difundindo-se para a periferia e outra que afirma que as inovações são produzidas pelas pequenas organizações; "que, menos organizadas, podem dar um curso mais livre a seu imaginário motor, a sua capacidade inventiva, e só são retomadas bem mais tarde pelas grandes organizações centrais".

No espaço de redes relacionais da inovação social agroecológica, o confronto entre singulares (inovações na grande organização e a confluência para a pequena organização) exige a reconfiguração de cada um dos atores envolvidos para se processar um ambiente de negociação organizacional em escala regional de difusão do conhecimento. Quando Enriquez (1997, p. 35) fala de organizações em ambientes locais, refere-se a uma "organização dinâmica como um agente de mudança na cultura local", o que, certamente, leva à construção de novas racionalidades e práticas, que atravessam as diferentes identidades e montam novos arranjos organizativos e identitários no espaço regional.

A produção do "novo", comumente difundido pelas políticas agrícolas, enquanto um singular criativo ou inovador, situa-se num contexto avesso à mera reprodução de um sistema social de difusão do conhecimento agroecológico. Para Hernández e Hernández (2010, p.38), “ as multiplicidades são a própria realidade, e não supõem nenhuma unidade, não entram em nenhuma totalidade e tampouco remetem a um sujeito". Para eles, as multiplicidades são o que caracteriza a existência social. Assim, por mais que haja subjetivações dominantes, sempre estão produzindo subjetivações múltiplas, com maior ou menor autonomia para negociar a propagação da multiplicidade de meios técnicos oriundos da agricultura sustentável.

A fim de auxiliar a socialização dos conhecimentos acumulados no decorrer do processo preparatório dos cultivos ecológicos e fomentar as capacidades interativas dos 
agricultores durante o processo de difusão regional da inovação agroecológica, torna-se imprescindível elaborar um conjunto de instrumentos de comunicação, o qual se configura nas associações e organizações promotoras da divulgação da produção agrícola (cooperativas e associações). As experimentações das famílias agroeocológicas ou mesmo de um grupo de agricultores(as) que têm suas inovações sistematizadas são levadas à descrição que interpreta suas realidades por meio de conversações informais articuladas pela assessoria ou pelas lideranças que integram as comissões de divulgação social das inovações e práticas agrícolas sociais. Essas conversas auxiliam a preparação das pessoas que apresentarão suas experiências em encontros e fornecem as informações necessárias para que as técnicas inovativas sociais geradas circulem numa capilaridade social mais intensa entre as regiões (SOUZA, 2010, p. 26).

Testemunha-se, hoje, a afirmação de um movimento social de inovação na forma agrícola de produção com base no intercâmbio, na troca horizontal de saberes e na constituição e estímulo às redes de conhecimento coletivo e solidário. Essas formas só são possibilitadas quando se integra o conhecimento produtivo agrícola ancestral à própria "ciência" praticada e desenvolvida por agricultores(as), que veem na sua criatividade do dia a dia a única alternativa para converter a forma de engendrar a difusão dos conhecimentos produtivos ancestrais e constituir um campo para a propagação regional dos elementos produtivos da agroecologia social.

\section{CONSIDERAÇÕES FINAIS}

O debate em torno do desenvolvimento do meio rural, no contexto atual, a partir de abordagens que permitam avançar além da antiga e ultrapassada concepção economicista e produtivista de desenvolvimento, predispõe um novo enfoque de desenvolvimento, que parte da revalorização dos saberes, tendo na agroecologia uma estratégia de promoção de técnicas e ações coletivas no meio rural.

As mobilizações sociais, com base nas inovações agroecológicas, permitiram que os produtores rurais de pequeno porte mantivessem os sistemas de cultivo ancestral. Estas formas de cultivo ancestral traziam elementos mais condizentes com a realidade socioambiental das comunidades rurais. No contexto de emergência da produção social agroeocológica, os agricultores desenvolvem a sua capacidade de lidar com as intempéries da baixa produção nos cultivos com base em um incremento criativo, pelo qual cada produtor utiliza o seu conhecimento ancestral e desenvolve conhecimentos técnicos específicos e aplicáveis em qualquer contexto ambiental.

Todo o processo advindo das melhorias produtivas agrícolas pela emergência da aprendizagem coletiva estabelece uma rede de difusão dos conhecimentos agroecológicos, ampliando a capilaridade das inovações sociais agrícolas às comunidades distantes. Esta forma de criação das redes de difusão do conhecimento agroecológico particulariza uma gama de atitudes afirmativas embasadas em experimentos agrícolas sociais e locais. 
No ambiente de aprendizado agroecológico, a regionalização das inovações técnicas sociais organiza o espaço no tocante à superação do impedimento idealizado pela expressão geográfica do agronegócio e da agricultura de precisão, gerando novos focos de autonomia produtiva e tecnológica social sem precisar submeter-se às políticas governamentais.

Destarte, na difusão espacial do conhecimento agroecológico social, as possibilidades criativas reduziram os gargalos técnico-inovacionais, estabelecendo os instrumentos ideais à autogestão coletiva da regionalização da produção agrícola sustentável. Desta feita, corresponde ao retorno das heranças culturais e das expectativas das quais os pequenos produtores rurais edificam o seu presente e projetam o seu futuro.

\section{REFERÊNCIAS}

ALMEIDA, S. G. de. Construção e desafios do campo agroecológico brasileiro. In: PERTERSEN, Paulo (org.). Agricultura familiar camponesa na construção do futuro. Rio de Janeiro: AS-PTA, 2009.

AMARAL FILHO, J. do. Cultura, criatividade e desenvolvimento. Políticas Culturais em Revista, v. 2, n. 1, 2009.

CAPORAL, F. R. et al. Agroecologia: matriz disciplinar ou novo paradigma para o desenvolvimento rural sustentável. Brasília, 2006.

ENRIQUEZ, E. Como estudar as organizações locais. In: FISCHER, T. (Org.). Gestão contemporânea: cidades estratégicas e organizações locais. 2. ed. Rio de Janeiro: Ed. 34, 1997.

FREIRE, A. G. et al. A sistematização no fortalecimento de redes locais de inovação agroecológica. Agriculturas, n. 2, julho, 2006.

GOMES, P. C. da C. O conceito de região e sua discussão. In: CASTRO, I. E.; GOMES, P. C. da C.; CORREAA, R. L. (Orgs.). Geografia conceitos e temas. Rio de Janeiro: Bertrand Brasil, 2010.

HERNÁNDEZ, J. M.; HERNÁNDEZ, M.J. B. Agricultura sustentável e a construção de conhecimentos locais: uma experiência em Jalisco, México. In: Agriculturas, v.7, março, 2010.

MARQUES, F. C. Aprendizagem e inovação: as várias faces do trabalho de produtores de plantas medicinais do Sul do Brasil. In: Agriculturas, outubro, 2009.

MOREIRA, R. J. Terra, poder e território. São Paulo: Editora Expressão Popular, 2007.

PERTERSEN, P. Construção do conhecimento agroecológico: novos papéis, novas identidades. Rio de Janeiro: Articulação Nacional de Agroecologia, 2007.

PERTERSEN, P. et al. A construção de uma Ciência a serviço do campesinato. In: familiar camponesa na construção do futuro. Rio de Janeiro: AS-PTA, 2009. (Org.). Agricultura

PLOEG, J. D. Sete teses sobre agricultura camponesa. In: PERTERSEN, P. (Org.). Agricultura familiar camponesa na construção do futuro. Rio de Janeiro: AS-PTA, 2009.

. O modo de produção camponês revisitado. In: SCHNEIDER, S. (Org.). A diversidade da agricultura familiar. Porto Alegre: Editora da UFRGS, 2006.

SCOTT , A. J. Cultural economy and the creative field of the city. In: Geografiska Annaler, Series B, Human Geography, v. 92, n. 2, 2010.

SOUZA, M. V. S. Tecendo a rede e construindo dinâmicas territoriais em Itapipoca. Agriculturas, v.7, março, 2010. 
WANDERLEY, M. N. B. Agricultura familiar e campesinato: rupturas e continuidade. Estudos Sociedade e Agricultura, Rio de Janeiro, n.2, 2009.

WEID, J. M. von der. Um novo lugar para a agricultura. In: PERTERSEN, P. (Org.). Agricultura familiar camponesa na construção do futuro. Rio de Janeiro: AS-PTA, 2009.

Recebido em 12/09/2011

Aceito para publicação em 22/11/2011 